Abstract 6 Table 1 CMR characteristics of Apical vs non-Apical HCM

\begin{tabular}{lllll}
\hline CMR findings: & $\begin{array}{l}\text { Total Cohort } \\
(\mathbf{n}=\mathbf{1 0 4})\end{array}$ & $\begin{array}{l}\text { Non-apical } \\
(\mathbf{n}=\mathbf{7 3})\end{array}$ & $\begin{array}{l}\text { Apical } \\
(\mathbf{n}=\mathbf{3 1})\end{array}$ & P-value \\
\hline Mean LVEF (\%) & 69.7 & 68.4 & 72.6 & 0.0552 \\
Mean LVEDVI (mL/m²) & 73.7 & 76.7 & 66.8 & 0.0718 \\
Mean LVESVI (mL/m²) & 23.8 & 25.5 & 20.1 & 0.1177 \\
Mean indexed stroke volume & 53.1 & 55.9 & 46.4 & 0.0333 \\
Mean max. LV wall thickness (mm) & 18.2 & 19.3 & 15.6 & 0.0001 \\
Mean indexed LV mass & 93.5 & 98.4 & 82.4 & 0.0102 \\
LVOTO & 35.2 & 41.1 & 12.5 & 0.0403 \\
SAM & 31.4 & 38.9 & 6.25 & 0.0143 \\
LGE (\%) & 86.9 & 85.7 & 89.7 & 0.8063 \\
\hline
\end{tabular}

LVEF, left ventricular ejection fraction; LVEDVI, left ventricular end diastolic volume index; LVESVI, left ventricular end systolic volume index; LVOTO, Left ventricular outflow tract obstruction; SAM, systolic anterior valve motion; LGE, late gadolinium enhancement.

Conclusions Our study suggests that prevalence of apical HCM is almost $1 / 3 \mathrm{rd}$ of all observed cases. It also demonstrates that prevalence of LGE was high in apical HCM, suggesting that better prognosis of apical HCM based on the absence of myocardial fibrosis, should be reconsidered. Further large trials are needed to better understand the pathophysiology.

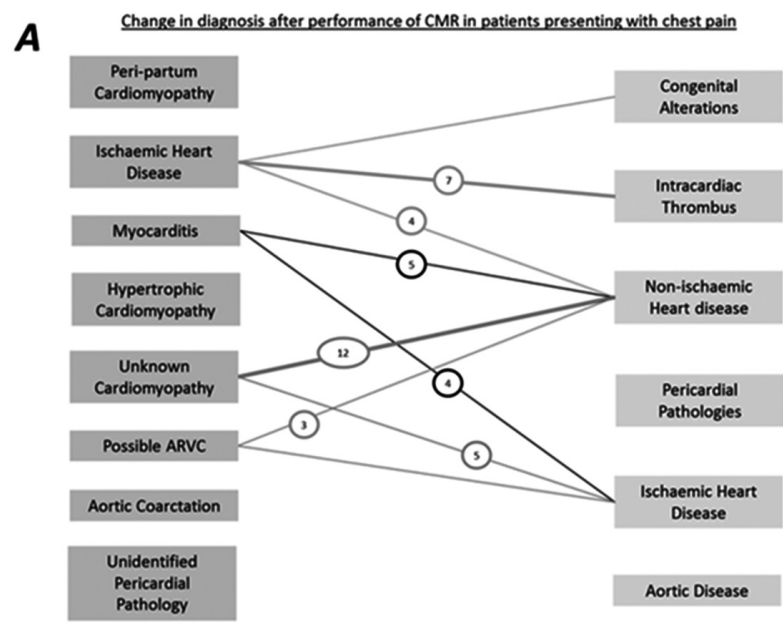

C

Change in diagnosis after performance of $\mathrm{CMR}$ in patients presenting arrhythmias/OOHCA/Syncope

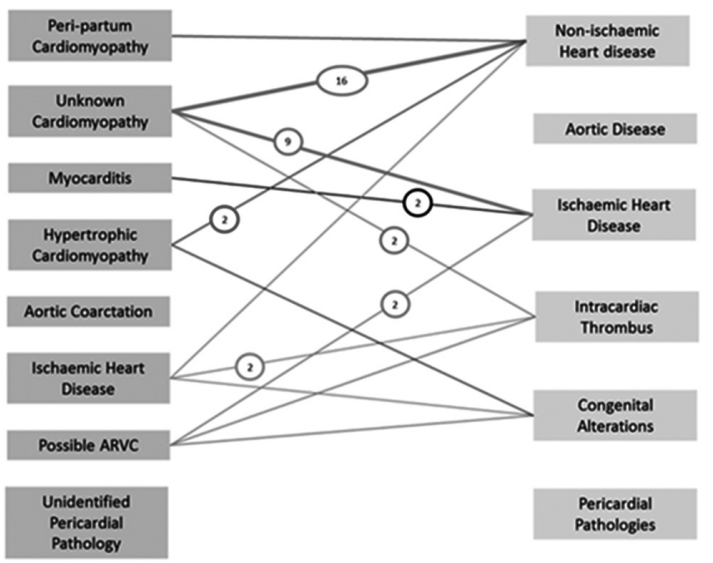

\begin{tabular}{ll}
\hline 7 & CLINICAL IMPACT OF CARDIOVASCULAR MAGNETIC \\
RESONANCE ON THE MANAGEMENT OF ACUTELY
\end{tabular} RESONANCE ON THE MANA
HOSPITALISED PATIENTS

*E De Garate, A Ghosh Dastidar, A Baritussio, A Scatteia, A Amadu, G Venuti, T Erdei, J Rodrigues, C Bucciarelli-Ducci. NIHR Bristol Cardiovascular Biomedical Research Unit, Bristol Heart Institute, Bristol, Avon, UK

\subsection{6/heartjnl-2016-309668.7}

Background Cardiac Magnetic Resonance (CMR) is invaluable for assessing ischaemic and non-ischaemic cardiomyopathies. However, evidence regarding the incremental impact of CMR in acutely hospitalised patients is scarce. We evaluated the impact of CMR on diagnosis and clinical decision-making in this cohort.

Methods We evaluated 2481 consecutive scans (Jan 2014-Dec 2014) at a large tertiary cardiothoracic centre, identifying 283 patients referred for inpatient scans. Protocol included short axis-long axis cines, T2-weighted oedema sequences, early and late gadolinium enhancement (LGE) images. Definitions for "significant clinical impact" of CMR included change in pre-CMR diagnosis, influence on hospitalisation period, change in medication and on decision making for invasive medical procedures (CABG, angiography, ICD implantation).

Results Of the 283 patients, 8 were excluded due to poor image quality, leaving 275 patients (66\% male, mean age 59yrs), mean ejection fraction of $46 \% \pm 19$. Patients underwent CMR for

B

Change in diagnosis after performance of CMR in patients presenting with shortness of breath

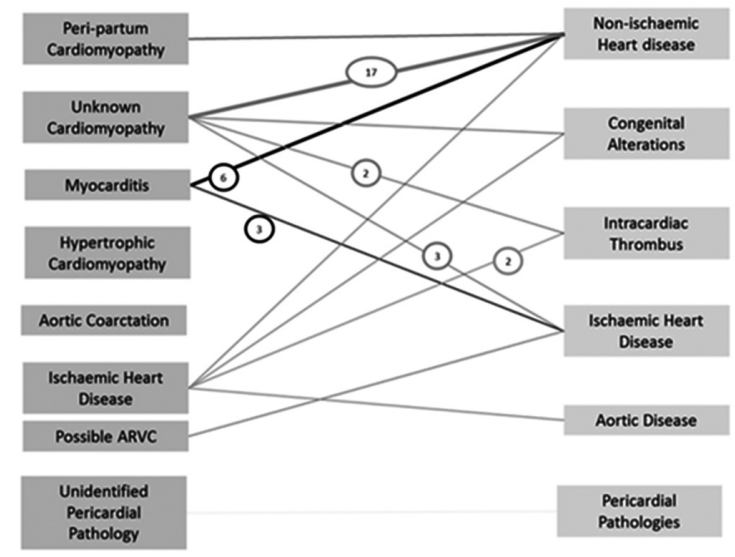

D

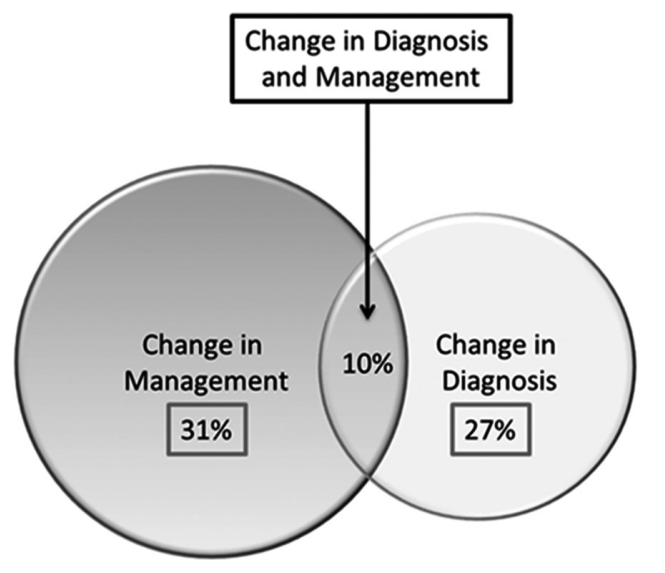

Abstract 7 Figure 1 Change in diagnosis after performing CMR in patients admitted with chest pain (A), shortness of breath (B) and arrhythmiasout of hospital cardiac arrest (C). (D) Overall significant clinical impact of CMR in change in management and new diagnosis 
further assessessment of ischaemic heart disease, cardiomyopathy or congenital heart disease. CMR demonstrated significant clinical impact on $68 \%$ of patients. This included a completely new diagnosis in $27 \%$ of patients, change in management in $31 \%$ and $10 \%$ of patients that had both a new diagnosis and change in management. CMR results promoted invasive procedures on $27 \%$, avoided invasive procedures on $16 \%$; and influenced on hospital discharge on $15 \%$ of the patients (Figure 1). $84 \%$ of the patients had echocardiography prior to CMR. CMR confirmed echo diagnosis in $11 \%$, complemented echo findings with significant new information in $41 \%$ and changed the echo diagnosis in $30 \%$ of the cases. In a multivariable model that included clinical/ imaging parameters, age and presence of LGE were the only independent predictors of "significant clinical impact" (LGE pvalue .007, OR 2.782, CI 1.328-5.828) (Table 1).

Conclusions CMR had significant impact in patient's diagnosis and management in $68 \%$ of acutely hospitalised patients. Presence of LGE was the only independent predictor of significant clinical impact following CMR.

Abstract 7 Table 1 Logistic Regression Variables in the Equation

\begin{tabular}{lllll}
\hline & Sig. & Odds ratio & \multicolumn{2}{l}{95 Conf. Interval } \\
\hline Sex & & & Lower & Upper \\
Age & .486 & .766 & .361 & 1.622 \\
Troponin & .028 & 1.026 & 1.003 & 1.050 \\
LVEF & .469 & 1.000 & 1.000 & 1.000 \\
iEDV & .945 & .999 & .972 & 1.027 \\
RWMA & .827 & 1.001 & .989 & 1.014 \\
LGE & .053 & 2.440 & .987 & 6.033 \\
Oedema & .007 & 2.782 & 1.328 & 5.828 \\
\hline
\end{tabular}

Variable(s): Sex, Age, Troponin, LVEF, iEDV, RWMA, LGE, Oedema.

\section{DIAGNOSTIC PERFORMANCE OF ECG DETECTION OF LEFT ATRIAL ENLARGEMENT IN PATIENTS WITH ARTERIAL HYPERTENSION RELATIVE TO THE CARDIAC MAGNETIC RESONANCE GOLD-STANDARD: IMPACT OF OBESITY}

${ }^{1, *} \mathrm{~T}$ Erdei, ${ }^{1} \mathrm{JC}$ Rodrigues, ${ }^{1} \mathrm{~B}$ McIntyre, ${ }^{1} \mathrm{~A}$ Ghosh Dastidar, ${ }^{2} \mathrm{AE}$ Burchell, ${ }^{2} \mathrm{~L}$ Ratcliffe, ${ }^{2} \mathrm{EC}$ Hart, ${ }^{2} \mathrm{JF}$ Paton, ${ }^{1} \mathrm{M}$ Hamilton, ${ }^{2} \mathrm{AK}$ Nightingale, ${ }^{1} \mathrm{NE}$ Manghat. ${ }^{1} \mathrm{CMR}$ Unit, NIHR Cardiovascular Biomedical Research Unit, Bristol Heart Institute, Bristol, UK; ${ }^{2}$ Cardionomics Research Group, Bristol Heart Institute, Bristol, UK

\subsection{6/heartjnl-2016-309668.8}

ECG may demonstrate evidence of left atrial enlargement (LAE), which has adverse prognostic implications. We sought to determine the accuracy of 5 ECG criteria of LAE in a hypertensive cohort relative to CMR and to investigate the confounding effect of obesity.

Methods Consecutive referrals for CMR from a tertiary hypertension clinic were reviewed. Patients with any concomitant cardiac pathology were excluded. ECGs were assessed, blinded to CMR data, for: 1) P wave $>110 \mathrm{~ms}, 2$ ) P-mitrale (notched P wave with inter-peak duration $>40 \mathrm{~ms}$ ), 3) $\mathrm{P}$ wave axis $<30^{\circ}$, 4) Area of negative $\mathrm{P}$ terminal force in lead V1 (NPTF-V1) $>40 \mathrm{~ms} \cdot \mathrm{mm}$ and 5) Positive P terminal force in aVL (PPTF-aVL) $>0.5 \mathrm{~mm}$. Maximal LA volume index (LAVI) was measured by the biplane area-length method.
Abstract 8 Table 1 A) Diagnostic performance of the various ECG parameters at detecting left atrial enlargement; B) Obesity subgroup analysis of diagnostic performance of the various ECG parameters at detecting left atrial enlargement

\begin{tabular}{|c|c|c|c|c|c|c|c|}
\hline \multicolumn{8}{|c|}{ A) Diagnostic performance of the various ECG parameters } \\
\hline & $\begin{array}{l}\text { Prevalence } \\
\text { ECG LAE } \\
(\%)\end{array}$ & $\begin{array}{l}\text { ROC-AUC } \\
\left(95^{\text {th }} \mathrm{Cl}\right)\end{array}$ & $\begin{array}{l}\text { Sensitivity } \\
(\%)\end{array}$ & $\begin{array}{l}\text { Specificity } \\
(\%)\end{array}$ & $\begin{array}{l}\text { PPV } \\
(\%)\end{array}$ & $\begin{array}{l}\text { NPV } \\
(\%)\end{array}$ & $\begin{array}{l}\text { ACC } \\
(\%)\end{array}$ \\
\hline$P>110 \mathrm{~ms}$ & 9 & $\begin{array}{l}0.497(0.384 \\
-0.610)\end{array}$ & 9 & 91 & 25 & 74 & 69 \\
\hline P mitrale & 1 & $\begin{array}{l}0.495(0.382 \\
-0.608)\end{array}$ & 0 & 99 & 0 & 74 & 73 \\
\hline $\mathrm{P}$ axis $<30^{\circ}$ & 27 & $\begin{array}{l}0.437(0.328 \\
-0.546)\end{array}$ & 18 & 70 & 17 & 71 & 56 \\
\hline $\begin{array}{l}\text { NPTF-V1 } \\
>40 \mathrm{~ms} . \mathrm{mm}\end{array}$ & 17 & $\begin{array}{l}0.465(0.355 \\
-0.576)\end{array}$ & 12 & 81 & 18 & 72 & 63 \\
\hline $\begin{array}{l}\text { PPTF-aVL } \\
>0.5 \mathrm{~mm}\end{array}$ & 8 & $\begin{array}{l}0.502(0.389 \\
-0.616)\end{array}$ & 9 & 92 & 27 & 74 & 70 \\
\hline $\begin{array}{l}\text { Any ECG } \\
\text { criteria for }\end{array}$ & 46 & $\begin{array}{l}0.387(0.279 \\
-0.495)\end{array}$ & 29 & 48 & 17 & 65 & 43 \\
\hline
\end{tabular}

LAE

B) Subgroup analysis by obesity

$P>110 \mathrm{~ms}$

$\begin{array}{llllll}\text { Non-obese } & 10 & 0.515(0.352 & 12 & 91 & 33\end{array}$

$\begin{array}{llllllll} & -0.679 & & & & & \\ \text { Obese } & 9 & 0.519(0.357 & 12 & 92 & 33 & 75 & 72\end{array}$

P mitrale

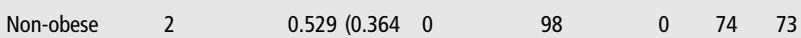

$\begin{array}{lllllll}\text { Obese } & 0 & -0.695) & & & & \\ & 0.500(0.340 & 0 & 100 & 0 & 75 & 75\end{array}$

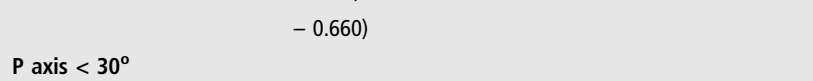

$\begin{array}{lllllllll}\text { Non-obese } & 21 & & 0.560(0.395 & 29 & 83 & 38 & 76 & 68 \\ & & -0.725) & & & & & \end{array}$

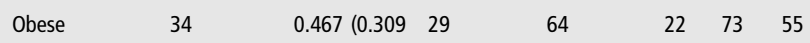

NPTF-V1 > 40

ms.mm

Non-obese

Obese

$-0.667)$

$-0.625)$

Results 130 patients were included (age: $51.4 \pm 15.1$ years, $47 \%$ male, 51\% obese, systolic blood pressure: $171 \pm 29 \mathrm{mmHg}$, 